\title{
Contribution of Foot Bath to Fatigue Relief Measured by Using Smart Phone Applied Questionnaires
}

\author{
Sukyong Seo ${ }^{1}$, Hyerin $\mathrm{Han}^{2}$ and Seunguk Yeon ${ }^{3, *}$ \\ ${ }^{1,2}$ College of Nursing, Eulji University, Korea \\ ${ }^{3}$ Department of Information Security, Seoul Women's University, Korea \\ ${ }^{1}$ sue.seo@gmail.com, ${ }^{2} 95215 @$ naver.com, ${ }^{3}$ seunguk@swu.ac.kr
}

\begin{abstract}
College students often sit for a considerably long time and experience poor blood circulation. This can cause edema that is a state of excessive deposits of moisture in the outer layer of cells and is known to be accompanied by fatigue in addition to the discomfort of the legs. Foot bath is an effective solution for fatigue alleviation by increasing cardiac parasympathetic activity, relaxation of muscle tension and easing tension in the brain. Although many studies have reported that foot bath effectively reduce fatigue, most focused on inpatients, elderly, and workers. Few studied for young students. This study aimed to examine the effect of foot-bath on fatigue relief among college students in Korea. All study participants asked to use their own smart-phones to fill out a set of questionnaires to evaluate the effect on fatigue. A quasi-experimental design was applied to compare the effect of foot bath for 56 participants (30 for experiments and 26 for controls). The experimental group was directed to foot bath for 20 minutes three times a week. We found that left leg edema of the experimental group decreased by $16.63 \pm 14.57 \mathrm{~mm}(p<.001)$. The right leg edema decreased by $13.10 \pm 13.97 \mathrm{~mm}(p<.001)$. There was no statistically significant difference in their fatigue level when comparing before and after performing foot baths. Foot bath can be an effective and economic way to decrease leg edema among young people. Smart-phone may help them to record their levels of fatigue and edema.
\end{abstract}

Keywords: Foot bath, Leg-edema, Fatigue relief

\section{Introduction}

Students often sit in the same posture for a long time and experience blood circulation not work well. Edema is a state of excessive deposits of moisture in the outer layer of cells [1]. It is known to be accompanied by fatigue in addition to the discomfort of the legs [2]. More than 80 percent of the disease is related to fatigue [3], and accumulated fatigue, resulting in the need to be dealt with in a timely manner, as it may result in a physiological and psychological distress.

According to the previous studies, young people may experience higher fatigue than older adults [5]. According to Kim et al., [5], Koreans in their 20s and 30s are more fatigued than those in their $40 \mathrm{~s}$ and $50 \mathrm{~s}$. Choi [8] warns that fatigue can develop chronic fatigue for college students if not treated in the proper way.

Foot bath is an effective solution for fatigue alleviation $[9,10]$. It results from increasing cardiac parasympathetic activity, relaxation of muscle tension and easing tension in the brain [9]. Above of all, foot bath is popular due to being easy for layman to perform at home and less costly than whole body bathing known as having similar effects $[11,12]$.

Received (October 7, 2018), Review Result (January 10, 2018), Accepted (January 30, 2018)

${ }^{*}$ Corresponding Author 
Previous studies have evaluated the effectiveness of foot bath focused on patients [13], old people [10, 17] middle-aged women [14], and emergency department nurses [15]. Few have studied young students. Lee [16] was as far as we knew the only researcher who targeted college students. The author pointed out that the fatigue of college students was significantly high and foot bath could be an effective way of coping with fatigue in college students' everyday life. Oh and Gang [2] and Kim and Park [13] also showed the effect of foot bath on younger adults' stress and fatigue relief, but they applied foot bath with a combination of aroma therapy, which is difficult to differentiate individual effect of foot bath excluding the effect of aroma therapy.

This study aimed to examine the effect of foot-bath on fatigue relief among college students in Korea. Study results are expected to shed light on developing an effective way to relieve fatigue for younger adults. By using an experimental study design with case-control groups, we seek for providing with robust empirical evidence on the effect of foot bath.

\section{Methods}

\subsection{Research Design and Study Participants}

This study is a quasi-experimental study to examine the effects of foot bath for college students on fatigue. The study participants were chosen among the college students who have seen our poster uploaded on SNS. They joined our research on a voluntary basis. Among about 40 respondents, we selected people who do not have any chronic disease and skin disease. Excluded were people who were currently taking a foot bath. 56 people who understood the purpose of our study and agreed to participate in our study were selected for the study. We randomly assigned 30 participants for experiment group, and 26 people for the comparison using the randomization function in the Excel program.

\subsection{Research Tools}

\subsubsection{Foot Bath Therapy}

The experiment group person was asked to perform a twenty-minute foot bath (soaking feet for six minutes, then performing foot massage for eight minutes and soaking the feet again for six minutes) two hours before going to bed. They were given an identical water bowl to carry similar amount of water. Foot massage was directed to perform prior to soaking feet: extending the tip of toes, scrubbing around peach bone and wiggling toes. They learned the massage procedure from a video clip provided in advance.

The foot bath procedure was previously examined the effect by researchers $[9,10$, 13], suggesting 10 to 15 minutes as an effective method in studies. In particular, Sung and Tochihara [9] reported that the foot bath method performed a great deal of stress before bedtime, and was reported to enhance the effectiveness in persistence of the foot bath if accompanied by a mechanical stimulus such as a massage.

\subsubsection{Leg Edema Measurement}

The same type of plastic tape ruler was provided to every person. The thickest and thinnest areas of both legs were chosen to measure the circumstance of legs. Edema was defined as the difference in the circumference of the thickest region and the periphery of the thinnest area [18]. 


\subsubsection{Fatigue Measurement}

Level of fatigue was directed for the study participants to measure by using a smart-phone application with a set of questionnaires developed for the purpose of evaluating fatigue. The questionnaire was composed of 12 questions originally developed by Oh and Gang [2]. Answers were measured by five point scales: 'Not at all ', 'Little bit', 'Fair', ' Quite a bit ', and 'Very much '. Scores range from 12 to 60 points, meaning that the higher the total score, the more elevated the fatigue level. The reliability of the instrument measuring fatigue level was measured for the original study [2] as Cronbach`s $\alpha=0.90$. In this study the Cronbach's $\alpha=0.88$ was measured. The time of fatigue measurement was determined following previous studies [9, 17]: the next morning after taking a foot bath at night.

\subsection{Data Collection and Procedures}

Data was collected from April 30 to May 22 in 2016. In order to protect personal information, every answer to the questionnaire and measurement records were directly sent to the research team. We visited the participants and explained the purpose and procedure of the study, and surveyed general characteristics and baseline levels of leg edema and fatigue. For the experiment group, a video clip demonstrating foot bath procedure was provided to educate them about the sequence and method of foot bath.

The experiment was conducted for a total of two weeks, and both the experimental and the control group recorded measurements using smart-phone applied questionnaire as scheduled. Fatigue was measured on the second, forth, and sixth day of the 2 nd week. The control group measured edema and fatigue in the same manner as in the experimental group. The measurement procedure is summarized in Figure 1.



Figure 1. Research Design 


\section{Results}

\subsection{Test of Homogeneity of Experimental Group Compared with Control Group}

\subsubsection{General Characteristics}

The homogeneity of the experimental group and control group was verified using t-test and Fisher's exact test. There was no significant difference between two groups (Table 1).

\subsubsection{Leg Edema and Fatigue}

The homogeneity of the experimental group and the control group before the experiment was tested in terms of degree of fatigue and degree of swelling of both lower limbs. There were no significant differences between the two groups (Table 2).

3.2. Changes in Underlying Edema and Fatigue before and after the Experimental Group and Control Group

As a result of applying the foot bath therapy, the leg swelling of the experimental group showed a significant decrease $(\mathrm{p}<.001)$ and the fatigue decreased slightly but did not show statistically significant change (Table 3 ).

The left leg swelling decreased by $16.63 \mathrm{~mm}$ on average and the right decreased by $13.10 \mathrm{~mm}$. The decrease in fatigue levels was 6.4 points compared to 3.4 points of the control group, but not statistically significant.

Table 1. Homogeneity Test of General Characteristics and Major Variables between Experimental and Control Groups( $\mathrm{N}=56)$

\begin{tabular}{|c|c|c|c|c|c|c|c|}
\hline \multirow[t]{2}{*}{ Variable } & \multirow[t]{2}{*}{ Subcategory } & \multicolumn{2}{|c|}{$\begin{array}{c}\text { Experimental } \\
\quad(n=30)\end{array}$} & \multicolumn{2}{|c|}{ Control $(n=26)$} & \multirow[t]{2}{*}{$\chi^{2} / t^{*}$} & \multirow[t]{2}{*}{$p$} \\
\hline & & $\mathrm{n}(\%)$ or & $\mathrm{M} \pm \mathrm{SD}$ & $\mathrm{n}(\%)$ or & $\mathrm{M} \pm \mathrm{SD}$ & & \\
\hline \multirow[t]{2}{*}{ Sex } & female & $25(83.3)$ & & $23(88.5)$ & & 0.29 & .712 \\
\hline & male & $5(16.7)$ & & $3(11.5)$ & & & \\
\hline Age(year) & & & $\begin{array}{c}19.34 \\
\pm .971\end{array}$ & 26 & $\begin{array}{l}20.04 \\
\pm 1.28\end{array}$ & - & .050 \\
\hline $\begin{array}{l}\mathrm{BMI}(\mathrm{kg} / \mathrm{m} \\
\left.{ }^{2}\right)\end{array}$ & & & $\begin{array}{l}21.63 \\
\pm .2 .21\end{array}$ & & $\begin{array}{l}22.10 \\
\pm .2 .1\end{array}$ & $-\overline{0.76}$ & .448 \\
\hline \multirow{3}{*}{$\begin{array}{l}\text { Ave. } \\
\text { Commutin } \\
\text { g time } \\
\text { (one-way) }\end{array}$} & $\begin{array}{l}\text { less than } \\
30 \mathrm{~min}\end{array}$ & $14(46.7)$ & & $10(38.5)$ & & 1.84 & .765 \\
\hline & $31-60 \mathrm{~min}$ & $7(23.3)$ & & $9(34.6)$ & & & \\
\hline & $\begin{array}{l}\text { longer than } \\
1 \mathrm{hr}\end{array}$ & $9(30.0)$ & & $7(26.9)$ & & & \\
\hline $\begin{array}{l}\text { Ave. } \\
\text { Standing } \\
\text { time(min) }\end{array}$ & & & $\begin{array}{l}102.43 \\
\pm 82.44\end{array}$ & & $\begin{array}{l}92.56 \\
\pm 86.59\end{array}$ & .73 & .667 \\
\hline Sleep time & less than $4 \mathrm{hr}$ & $1(3.3)$ & & $0(0.0)$ & & 1.32 & .724 \\
\hline
\end{tabular}




\begin{tabular}{|c|c|c|c|c|c|}
\hline & $4-6 \mathrm{hr}$ & $14(46.7)$ & $11(42.3)$ & & \\
\hline & $6-8 \mathrm{hr}$ & $13(43.3)$ & $12(46.2)$ & & \\
\hline \multirow{4}{*}{$\begin{array}{l}\text { Alcohol } \\
\text { drinking }\end{array}$} & $\begin{array}{l}\text { longer than } \\
8 \mathrm{hr}\end{array}$ & $2(6.7)$ & $3(11.5)$ & & \\
\hline & never & $2(6.7)$ & $5(19.2)$ & 3.59 & .308 \\
\hline & once a week & $23(76.7)$ & $19(73.1)$ & & \\
\hline & $2+$ weekly & $5(16.7)$ & $2(7.7)$ & & \\
\hline \multirow[t]{2}{*}{ Smoking } & no & $26(86.7)$ & $24(92.3)$ & .99 & .553 \\
\hline & yes & $4(13.3)$ & $2(7.7)$ & & \\
\hline \multirow[t]{3}{*}{ Salt intake } & High & $14(46.7)$ & $9(34.6)$ & 2.40 & .661 \\
\hline & Moderate & $11(36.7)$ & $12(46.2)$ & & \\
\hline & Low & $5(16.7)$ & $5(19.2)$ & & \\
\hline \multirow[t]{3}{*}{$\begin{array}{l}\text { General } \\
\text { health }\end{array}$} & $\begin{array}{l}\text { Excellent+ve } \\
\text {-ry good }\end{array}$ & $8(26.6)$ & $11(42.3)$ & 3.09 & .377 \\
\hline & good & $18(60.0)$ & $14(53.8)$ & & \\
\hline & fair+poor & $4(13.3)$ & $1(3.8)$ & & \\
\hline \multirow[t]{3}{*}{$\begin{array}{l}\text { Foot } \\
\text { health }\end{array}$} & Very good & $11(36.7)$ & $12(46.1)$ & 7.51 & .057 \\
\hline & good & $13(43.3)$ & $7(26.9)$ & & \\
\hline & poor & $6(20.0)$ & $7(26.9)$ & & \\
\hline \multirow[t]{3}{*}{$\begin{array}{l}\text { Swelling } \\
\text { feet }\end{array}$} & no & $3(10.0)$ & $6(23.0)$ & 2.81 & .420 \\
\hline & sometimes & $19(63.3)$ & $16(61.5)$ & & \\
\hline & yes & $8(26.7)$ & $4(15.4)$ & & \\
\hline \multirow[t]{3}{*}{ Cold feet } & no & $2(6.7)$ & $3(11.5)$ & 2.47 & .481 \\
\hline & sometimes & 11(36.7) & $8(30.8)$ & & \\
\hline & yes & $17(56.7)$ & $15(57.7)$ & & \\
\hline \multirow[t]{2}{*}{$\begin{array}{l}\text { Stress rel. } \\
\text { disease }\end{array}$} & no & $25(83.3)$ & $19(73.1)$ & 5.05 & .409 \\
\hline & yes & $5(16.6)$ & $7(26.9)$ & & \\
\hline
\end{tabular}

* Fisher's exact test was applied when expected frequency was less than 5 in a cell. 
Table 2. Result from Paired t test of Leg Edema and Fatigue between Experimental and Control Groups( $\mathrm{N}=56)$

\begin{tabular}{|c|c|c|c|c|c|c|}
\hline \multirow{2}{*}{ Variable } & & Pre & Post & Difference & \multirow{2}{*}{$\mathrm{t}$} & \multirow{2}{*}{$p$} \\
\hline & & $\mathrm{M} \pm \mathrm{SD}$ & $\mathrm{M} \pm \mathrm{SD}$ & $\mathrm{M} \pm \mathrm{SD}$ & & \\
\hline \multirow[t]{2}{*}{$\begin{array}{l}\text { Left leg } \\
\text { edema }\end{array}$} & $\begin{array}{l}\text { Experimental } \\
\text { group }(n=30)\end{array}$ & $\begin{array}{l}140.10 \\
\pm 28.58\end{array}$ & $123.47 \pm 33.68$ & $16.63 \pm 14.57$ & 6.25 & $<.001$ \\
\hline & $\begin{array}{l}\text { Control } \\
\text { group }(n=26)\end{array}$ & $\begin{array}{l}139.23 \\
\pm 31.88\end{array}$ & $140.18 \pm 30.90$ & $-.95 \pm 2.66$ & -1.68 & .108 \\
\hline \multirow[t]{2}{*}{$\begin{array}{l}\text { Right } \\
\text { leg } \\
\text { edema }\end{array}$} & $\begin{array}{l}\text { Experimental } \\
\operatorname{group}(n=30)\end{array}$ & $\begin{array}{l}138.67 \\
\pm 30.54\end{array}$ & $125.57 \pm 35.91$ & $13.10 \pm 13.9$ & 5.13 & $<.001$ \\
\hline & $\begin{array}{l}\text { Control } \\
\text { group }(n=26)\end{array}$ & $\begin{array}{l}137.86 \\
\pm 32.40\end{array}$ & $137.09 \pm 32.00$ & $.77 \pm 4.16$ & .871 & .394 \\
\hline \multirow[t]{2}{*}{ Fatigue } & $\begin{array}{l}\text { Experimental } \\
\text { group }(n=30)\end{array}$ & $\begin{array}{l}26.9 \\
\pm 8.70\end{array}$ & $19.23 \pm 6.70$ & $-6.4 \pm 10.17$ & -1.42 & .161 \\
\hline & $\begin{array}{l}\text { Control } \\
\text { group }(n=26)\end{array}$ & $\begin{array}{l}21.95 \\
\pm 7.82\end{array}$ & $18.55 \pm 8.13$ & $-3.4 \pm 5.37$ & -1.36 & .181 \\
\hline
\end{tabular}

\section{Discussion and Conclusions}

The purpose of this study was to examine the effect of foot bath therapy on the subject's lower extremity edema and fatigue in university students. The foot swelling was significantly reduced after a total of 3 times of foot bathing for one week every other day. Similar result was found from other studies [14-16] that have significant effects on lower extremity edema. Son [14] and Lee et al. [15] studied middle-aged women and 30-year-old women, respectively. This study confirmed that footbaths were effective for relatively young college students in their $20 \mathrm{~s}$. These results confirm that footbath is an effective way to reduce lower extremity edema in college students. Therefore, foot bath would be helpful to alleviate physical and emotional constraints due to edema.

In this study, subjects were able to perform footbath three times a week and to relieve lower extremity edema. Son [14] compared the results of three weeks of intervention and Lee et al., [16] conducted 12-week foot-bath for 3 weeks. Ha [12] also found that footbaths had the advantage of being effective in a relatively short period of time.

The short-term intervention is thought to have an important potential in the development strategy of the nursing intervention law [12]. Nurses can recommend foot baths to patients who want immediate improvement in lower extremity edema. In addition, by temporarily alleviating the negative sensation through the footbath, patients can be helped to endure the treatment process which requires patience and long time [13].

As patients' interest in complementary alternative therapies such as foot baths has increased, various studies have been conducted to apply them to nursing interventions. Kim [13] studied the effects of foot bath therapy as a nursing intervention for inpatients. This paper suggests that the more the number of interventions, the greater the effect of footbaths, suggesting the possibility of application as a nursing intervention in footbath therapy. In the case of Seo [17], 
footbath was performed as a sleep-inducing nursing intervention in a nursing home setting and its effect was reported. In addition, it is not difficult to find an example of using a foot bath for nursing intervention as an overseas study [10]. The nurse's interest in using footbaths is expected to be even higher, considering that noninvasive methods are used and the cost burden is relatively small [17].

In many previous studies, foot bath therapy was conducted in parallel with other treatments rather than practiced alone. In Oh and Gang [2], aroma oil was mixed with water, while Kim and Park [13] used lavender oil. The authors applied six minutes of foot bath followed by a 6-minute massage and a half body bath for six minutes. It was difficult to find a prior study on whether or not to have a foot drop in warm water without parallel therapy. Further research is needed such as SaekI [9] and Suchihara [10], which evaluated the effects of foot bath in terms of blood circulation, relaxation, and sleep. If the footbath alone can have a positive effect without additional concurrent therapy that requires additional costs and procedures, it would be an effective nursing intervention method that is both easy to apply and cost effective.

On the other hand, the fatigue level showed no difference between the experimental group and the control group. This is consistent with Oh and Gang [2], who showed that foot bath therapy did not significantly reduce psychological stress of nurses in the operating room, and Lee [15] that foot bath therapy did not significantly reduce physical stress psychological stress and fatigue of examinees. However, for Seo and Sohng [17], the foot bath was somewhat effective in reducing the fatigue of the elderly residing in institutions. The conflicting results originated from differences in experimental design, arbitration and target characteristics. Since fatigue, the dependent variable, was based on subjective feelings, there was confounding psychological effect coming from weather, daily event, and other unknown psychosocial factors related to fatigue [11]. Seo and Sohng [17] studied elderly people living in a nursing home. In this case, the experimental group and the control group were considered to be under a comparatively homogeneous environmental influence.

In many previous studies, foot bath therapy was conducted together with other treatments rather than practiced alone. In the case of Oh and Gang [2], the mixture of fermented extract or oil was mixed with water, while Kim and Park [13] used lavender oil. In this case, it is difficult to find whether or not foot bath is effective when performed alone. If the footbath alone can have a positive effect without additional concurrent therapy that requires additional costs and procedures, it would be helpful for people to treat their suffering from edema in an easy and cost effective way.

This study is based on the study sample collected by using the convenience extraction method, and there is a limit to generalization of the result as whole students. The results of this study were as follows: 1) the number of subjects was not enough, 2) subjects were dropped during the study period, 3) university students in the whole country, but most of the subjects were E students, The point of not being able to consider the increase of the circumference of the lower limb temporarily due to the water after the footbath, the type of the shoe, the special condition of the individual (test period, physical competition, etc.) This is a limitation in generalizing the results of this study.

The limitations of this study are that the results are underestimated or overestimated by the influence of other variables not controlled by the research method. The homogeneity between the study group and the control group was confirmed only in a very limited area. As described in the research method, we controlled the demographic characteristics (age, sex), health status (subjective health status, stress related illness), health behavior factors (sleep pattern, smoking, 
drinking, exercise) It is not possible to rule out the possibility that the influence of other factors (e.g., weather on the day of the experiment, occurrence of a specific life event, psychological change) In addition, according to Park [6], stress of college students in Korea is closely related to 'college life factors' such as academic problems, economic problems, and value problems. This factor of life and the fatigue which is the main variable of this study can have a little correlation. Above all, to prevent overestimation of the results by the experimental effects, the control group was instructed to take vitamins as a type of placebo, which could not be ruled out as a result of fatigue reduction and lowering of lower extremity edema. Therefore, it is necessary to pay attention to the interpretation of the results of this study, which are not fully controlled by the influence of these other variables.

The study focused on easing college students 'lower limb swelling. If you look at pre-embedding studies, it is difficult to search the subject of university students. Both Son[14] and Lee[15] are targeting middle-aged women and women in their 30s and this study is considered to contribute to the fact that it expanded their research targets. The need for university students to be studied can be described as the specifics of the Republic of Korea's university students. Students in Korea tend to have high levels of stress on their academic careers and sit for long time [5]. Acute stress and long sitting postures cause problems in the circulation of the lower extremities [2], resulting in lower extremity edema, subcutaneous fat accumulation, and fatigue [1]. In addition, they are in development and normal young adults, and are in a situation where they must continue to make autonomous decisions. Academic problems, economic problems, and values are also important stress factors that increase the daily life fatigue of college students [6]. Considering that persistent stress can result in health imbalance and may affect the incidence of various diseases [3], college students need to address edema and fatigue. In particular, fatigue is a common experience among people in everyday life, and it is one of the frequent complaints that the severity of health problems tends to be neglected. However, if the fatigue is accumulated for a long time, it may cause physiological and psychological changes and cause health problems, so it needs to be solved in a timely manner [4]. According to Kim et al. [5], Korean youths in their $20 \mathrm{~s}$ and 30s are more fatigued than those in their 40s and 50s. Choi [8] asserted that especially fatigue of college students should be treated as an important aspect of health care. It is not only necessary to develop nursing intervention to effectively prevent the fatigue of college students before they become chronic fatigue, but further study is needed on how to maintain the health promotion lifestyle of the tired subject.

Experiment participants performed footbath for a week in this study. Son [14] reported the results of 3-week foot bath and Lee et al., [16] conducted 12-week foot bath. Although Ha [12] argued that footbaths had an immediate effect of relieving edema and fatigue, our study period may be too short to bring up significant changes. Further research needs to perform for a prolonged study period

Fatigue showed no difference between the experimental group and the control group. This result is consistent with Oh and Gang [2], who showed that foot bath therapy did not significantly reduce psychological stress of nurses in the operating room. Lee [15] also reported that foot bath therapy did not significantly reduce physical stress psychological stress and fatigue of examinees. However, for Seo and Sohng [17], the foot bath was somewhat effective in reducing the fatigue of the elderly in the facility. These conflicting results may originate from differences in experimental design, operational definition of foot bath, environment, and study participants. They also came from the fact that fatigue was measured based on subjective feelings. Future researchers consider the effect of other psychosocial factors related to measure fatigue to verify the effect of foot bath on fatigue. 
The limitations of this study are more than one. The homogeneity between the study group and the control group was confirmed only in a very limited area. Although tested their demographic characteristics (age, sex), health status (health status, chronic diseases), health behavior factors (sleep pattern, smoking, drinking, exercise), other important potential factors should be considered (weather on the day of the experiment, occurrence of a specific life event, psychological change). According to Park [6], stress of college students in Korea is closely related to 'college life factors' such as academic problems, economic problems, and value problems. Therefore, our findings would be applied with significant consideration.

\section{Acknowledgments}

This paper is a revised and extended version of a paper entitled "Evaluation of the Effect of Foot Bath by using Smart Phone Applied Questionnaires" presented at The $9^{\text {th }}$ International Conference on Future Generation Information Technology, Daejeon University, Korea, Dec.21-23, 2017. This work was supported by a research grant from Seoul Women's University (2018).

\section{References}

[1] M. A. Choi and K. S. Kim, "Nursing Science”, Seoul: Seoul Nat'l University Press, (1997), pp. 45-62.

[2] H. S. Oh and G. H. Gang, "Effects of Foot Baths on Stress and exhaustion for high school senior students", Journal of Academia-industrial Technology., vol. 11, no. 1, (2010), pp. 402-408.

[3] L. Cameron, E. A. Leventhal, and H. Leventhal, "Seeking medical care in response to symptoms and life stress", Psychosomatic Medicine., vol. 57, (1995), pp. 37-47.

[4] F. C. Dimeo, "Effect of exercise on cancer-related fatigue", American Cancer Society, vol. 92, no. 6, (2001), pp. 1689-1693.

[5] O. S. Kim, A. J. Kim, S. W. Kim, S. Baik and K. M. Yang, "Fatigue, depression and sleep in young adult and middle-aged", Journal of Korean Academy of Nursing, vol. 33, no. 5, (2003), pp. 618-624.

[6] P. N. Park, "The meditating effect of stress coping type and self-seem between life stress and suicidal ideation in nursing college student”, Journal of Korean Society of School Health., vol. 29, no. 1, (2016), pp. 1-10.

[7] J. R. Wichianson, S. A. Bugh, J. B. Unger, D. Spruit-Metz and S. T. Nguyen-Ro-driguez, "Perceived stress, coping and night-eating in college students", Stress and Health, vol. 25, (2009), pp. 235-240.

[8] J. Choi, "Fatigue and fatigue-regulation behaviors of undergraduates in courses related to public health and undergraduates in courses not related to public health", Journal of Korean Academy of Fundamentals of Nursing., vol. 6, no. 1, (2009), pp. 83-91.

[9] Y. Saeki, "The effect of footbath with or without the essential oil of lavender on the autonomic nervous system: a randomized trial”, Complementary therapies in medicine, vol. 8, no. 1, (2000), pp. 2-7.

[10] E. J. Sung and Y. Tochihara, "Effects of bathing and hot footbath on sleep in winter", Journal of Physiological Anthropology and Applied Human Science, vol. 19, (2000), pp. 21-27.

[11] W. S. Chung, "Seasonal difference of feet immersion effect in terms of thermal comfort", The Korean Society of Community Living Science Conference Proceedings, (2009), pp. 72.

[12] J. M. Ha, "The Effect of foot Bath on male workers' stress and mental and physical relaxation", Unpublished master's thesis, Sungshin University, Seoul, (2010).

[13] D. S. Kim and I. S. Park, "Foot reflexology for the intervention of sensations after breast cancer surgery", Journal of Korean Oncology Nursing., vol. 10, no. 2, (2010), pp. 180-190.

[14] K. Y. Son, "The Effect of foot bath on stress and lower extremity edema of middle-aged women", Journal of Korean Society of Aesthetics and Cosmetics, vol. 6, no. 1, (2011), pp. 29-41.

[15] Y. S. Lee, H. K. Park, H. J. Kim and Y. H. Jung, "Effects of foot bath therapy on operating room nurses' lower extremities edema, stress, and fatigue", Journal of Korean Clinical Nursing Research, vol. 20, no. 1, (2014), pp. 102-112.

[16] Y. J. Lee, J. S. Kweon and S. J. Yu, "The Effect of foot-bath on fatigue in nursing students on clinical practice”, Journal of Korean Nursing Education, vol. 9, no. 1, (2003), pp. 94-102.

[17] H. S. Seo and K. Sohng, "The effect of footbath on sleep and fatigue in older Korean adults", Journal of Korean Academy of Fundamentals of Nursing, vol. 18, no. 4, (2011), pp. 488-496. 
[18] H. S. Oh, "Effects of Foot baths on lower extremity edema, stress, and exhaustion for high school senior students", Unpublished master's thesis, Hansung University, Seoul, (2009).

[19] S. Seo and S. Yeon, "Evaluation of the Effect of Foot Bath by using Smart Phone Applied Questionnaires", Proceedings of the 9th International Conference on Future Generation Information Technology, Daejeon University, Korea, (2017) December 21-23.



\section{Authors}

Sukyong Seo, $\mathrm{PhD}$, RN

-Feb. 1998 : Master's degree of Public Health from Seoul Nat'l Univ., Seoul, Korea

-May. 2007 : PhD from School of Publid Health, UC Berkeley, CA, USA

-Sept. 2014-current : Assistant professor of Community Public Health Nursing, Eulji Univ., Sungnam-si, Korea

$<$ Research Interests> : Health Education, Chronic Disease Management, Health Economics

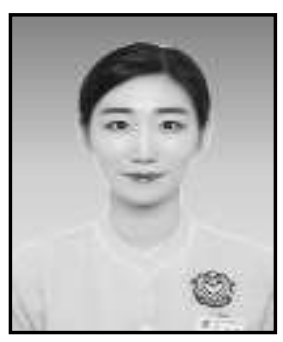

\section{Hyerin Han}

-March 2014 - current : Student of College of Nursing, Eulji Univ., Sungnam-si, Korea



\section{Seunguk Yeon, ME}

-Aug. 1992: Bachelor's degree of Computer Engineering from Seoul Nat'l Univ., Seoul, Korea

-Aug. 1994: Master's degree of Computer Engineering from Yonsei Univ., Seoul, Korea

-Oct. 2016-current : Assistant professor of Information Security, Seoul Women's Univ., Seoul, Korea

<Research Interests> : Massive Server Programming, Cloud Computing, Database, IoT 